\title{
Titanium Trisulfide Nanoribbons Affect the Downy Birch and Poplar $\times$ Aspen Hybrid in Plant Tissue Culture via the Emission of Hydrogen Sulfide
}

\author{
Olga V. Zakharova ${ }^{1,2,3, *}$, Alexander A. Gusev ${ }^{1,2,4}{ }^{\oplus}$, Dmitry S. Muratov ${ }^{2}\left(\right.$, Alexey V. Shuklinov ${ }^{1}$, \\ Nataliya S. Strekalova ${ }^{1}$ and Sergey M. Matveev ${ }^{4}$ \\ 1 Institute for Environmental Science and Biotechnology, Derzhavin Tambov State University, \\ 392000 Tambov, Russia; nanosecurity@mail.ru (A.A.G.); tambovbest@yahoo.com (A.V.S.); \\ kotova-ns@yandex.ru (N.S.S.) \\ 2 Department of Functional Nanosystems and High-Temperature Materials, National University of Science and \\ Technology “MISIS”, 119991 Moscow, Russia; muratov@misis.ru \\ 3 Engineering Center, Plekhanov Russian University of Economics, 117997 Moscow, Russia \\ 4 Research Educational Center Sustainable Development of the Forest Complex, Voronezh State Forestry \\ University Named after G F Morozov, 394087 Voronezh, Russia; lisovod@bk.ru \\ * Correspondence: olgazakharova1@mail.ru; Tel.: +7-961-618-93-79
}

\section{check for} updates

Citation: Zakharova, O.V.; Gusev, A.A.; Muratov, D.S.; Shuklinov, A.V.; Strekalova, N.S.; Matveev, S.M. Titanium Trisulfide Nanoribbons Affect the Downy Birch and Poplar $\times$ Aspen Hybrid in Plant Tissue Culture via the Emission of Hydrogen Sulfide. Forests 2021, 12, 713. https://doi.org/10.3390/ f12060713

Academic Editor: Stefan Arndt

Received: 16 April 2021

Accepted: 28 May 2021

Published: 31 May 2021

Publisher's Note: MDPI stays neutral with regard to jurisdictional claims in published maps and institutional affiliations.

Copyright: (c) 2021 by the authors. Licensee MDPI, Basel, Switzerland. This article is an open access article distributed under the terms and conditions of the Creative Commons Attribution (CC BY) license (https:// creativecommons.org/licenses/by/ $4.0 /)$.

\begin{abstract}
Plant tissue culture is an important tool for accelerated vegetative reproduction of woody plants. To increase the efficiency of this method, it is necessary to search for new growth stimulators and protectors of microshoots. Two-dimensional (2D) nanomaterials are highly promising for applications in medicine and biotechnologies. We have studied the effects of $\mathrm{TiS}_{3}$ nanoribbons with the following mean dimensions: thickness less than $100 \mathrm{~nm}$, length 1-10 $\mu \mathrm{m}$ and width 0.4-1 $\mu \mathrm{m}$ upon poplar $\times$ aspen hybrid and downy birch microclones in plant tissue culture. We have found the effectiveness of this particular nanomaterial as a sterilizing and stimulating agent in the initial growth stage and as a rhizogenesis-activating agent in the rooting stage. We analyzed a wide range of $\mathrm{TiS}_{3}$ concentrations in the nutrient media and identified $1.5 \mathrm{and} 3 \mu \mathrm{g} / \mathrm{L}$ as optimal. However, concentration-dependent toxic effects manifesting themselves through microclones viability suppression have been discovered in the groups exposed to 6 and $15 \mu \mathrm{g} / \mathrm{L} \mathrm{TiS}_{3}$. We have established that plant reaction to $\mathrm{TiS}_{3}$ treatment is specific for different plant species, i.e., downy birch is generally more tolerant than poplar $\times$ aspen hybrid. Here, we propose that the protective and stimulating effects of titanium trisulfide as well as its toxicity in high concentrations can be explained by the release of hydrogen sulfide as a result of aqueous hydrolysis of nanoribbons and its effect on plants. Additional studies are required in order to assess all biological effects produced by $\mathrm{TiS}_{3}$ nanoribbons at further stages of ontogenetic development and to identify the mechanisms of their action.
\end{abstract}

Keywords: downy birch; poplar $\times$ aspen hybrid; plant tissue culture; 2D transition metal chalcogenides; $\mathrm{TiS}_{3}$ nanoribbons; sterilizing and stimulating agent; hydrogen sulfide

\section{Introduction}

The downy birch (B. pubescens Ehrh.) is typical in northern regions [1] and provides raw material for paper and paperboard, pulp, plywood, veneer and sawn goods, particle board, fiberboard and firewood [2]. Poplars (genus Populus) are the model organisms for forest biotechnology, and genetic modification is more advanced for this genus than other trees [3]. Poplar and its hybrids are useful for energetic plantations [4] and the phytoremediation of soils [5] and as ornamental plants [6]. The selection of the best clonal lines and genotypes for more effective breeding of species such as birch, poplar and its hybrids should be accompanied by more convenient and productive methods of vegetative propagation. Despite many years of research in the field of plant tissue culture, callus induction, organogenesis and somatic embryogenesis of adult birches and poplars, like 
other hardwood trees, are still limited by genotypic, physiological and environmental factors [7-10]. Here, the main problem is the low production of viable plantlets from somatic embryos. The culture media and environmental conditions have not yet been optimized for many species/genotypes, and the use of alternative or new chemicals may prove to be more effective than conventional culture media [11]. Therefore, many studies have been devoted to the search for new stimulators of micropropagation of these species [12-16].

Multiple examples prove that nanomaterials can be successfully applied in plant tissue culture $[17,18]$. Nanoparticles (NPs) are widely used to boost seed germination and enhance plant growth and yield, and they can facilitate genetic modifications, improve bioactive substances production and provide plant protection against diseases [19-21]. There are reports showing that treatment with NPs removes microbial contaminants from explants and promotes such processes as callus induction, organogenesis, somatic embryogenesis, etc. [22]. It has been shown that the treatment of arabidopsis seeds, potato leaves and tomato cotyledons with $100 \mathrm{mg} / \mathrm{L}$ silver NPs for 1 and 5 min resulted in 100\% decontamination of the samples without affecting their viability [23]. Silver NPs added at $4 \mathrm{mg} / \mathrm{L}$ to the growing medium reduced phytopathogenic activity in olive explants and had no adverse effects on the plantlets [24]. Additionally, pathogen-free cultures were obtained when potato and tobacco axillary buds were disinfected and cultivated in MS media with added titanium dioxide [25]. A number of research works have revealed a positive effect of nanoparticles on callus induction and on shoots regeneration and growth. For example, the visual inspection of Tecomella undulata explants grown in MS media with $10 \mathrm{mg} / \mathrm{L}$ silver $\mathrm{NPs}, 2.5 \mathrm{mg} / \mathrm{L}$ 6-benzylaminopurine (BAP) and $0.1 \mathrm{mg} / \mathrm{L}$ indole acetic acid (IAA) revealed an increase in the mean number of fresh shoots per explants, in the percentage of explants producing shoots and in callus formation [26]. Copper NPs at $0.5 \mathrm{mg} / \mathrm{L}$ and cobalt NPs at $0.8 \mathrm{mg} / \mathrm{L}$ were added to MS nutrient medium and led to an increase in microplant height, the quantity of internodes and the quantity of shoots and to the improved rooting activity of Mentha longifolia [27]. In the study performed on Stevia rebaudiana internode explants, the highest percentage of shoot formation (89.6\%) was obtained at $1 \mathrm{mg} / \mathrm{L}$ of $\mathrm{ZnO}$ nanoparticles concentration in MS medium [28]. The exploration of the potential effects of multiwalled carbon nanotubes (MWCNTs) on callus induction in Satureja khuzestanica leaf explants has revealed a significant improvement in callus growth in Gamborg's B5 medium treated with $25-50 \mu \mathrm{g} / \mathrm{mL}$ of the nanomaterial, while higher concentrations of the material (100-500 $\mu \mathrm{g} / \mathrm{mL})$ reduced callus biomass [29]. Khodakovskaya et al. [30] reported a $64 \%$ increase in tobacco explants callus growth upon treatment with $100 \mu \mathrm{g} / \mathrm{mL}$ MWCNTs compared to the control. The authors found a correlation between the activation of cell growth exposed to MWCNTs and the upregulation of genes involved in cell division $(\mathrm{CycB})$, cell wall formation (NtLRX1) and water transport (NtPIP1).

At the same time, there is evidence of the phytotoxicity of nanoparticles of various types [31,32], including titanium-based nanoparticles. $\mathrm{TiO}_{2}$ nanoparticles inhibited the rate of seed germination of tomatoes [33], peppermint [34], maize and Narbonne peas [35] and disrupted microtubular networks in Arabidopsis thaliana root cells [36].

There are a limited number of research works on the effects of transition metal di- and trichalcogenides on plants. For example, one study showed that $\mathrm{MoS}_{2}$ had a negligible impact on rice seed germination rate, malonaldehyde (MDA) content and antioxidant enzyme activity [37]. However, the length and biomass of rice root and shoot, chlorophyll content index and expression of aquaporin genes were significantly increased. The authors concluded that $\mathrm{MoS}_{2}$ promoted rice growth through the promotion of nitrogen source assimilation, the enhancement of photosynthesis, enzymatic-related biochemical reactions, metabolic processes and, subsequently, the acceleration of cell division and expansion.

We screen a wide range of nanoparticles as potential growth promoters and protectors of woody plants during micropropagation $[38,39]$. A previous study has revealed the positive effect of zirconium trisulfide $\left(\mathrm{ZrS}_{3}\right)$ on explants of white poplar $\times$ aspen hybrid, birch, willow, oak and pine [39]. At the same time, in another recent study on bacte- 
ria [40], we discovered an interesting mechanism of the biological effects of transition metal trichalcogenides, associated with the slow emission of hydrogen sulfide from the surface of the nanomaterial. As the first study of this phenomenon in plants, here we evaluated the effects of a promising 2D material, namely, titanium trisulfide $\left(\mathrm{TiS}_{3}\right)$ nanoribbons, on white poplar $\times$ aspen (Populus alba $\times$ Populus tremula) hybrid and downy birch (Betula pubescens) regenerants at various microcloning stages to search for new effective and safe stimulants of vegetative propagation for these important forest trees.

\section{Materials and Methods}

The studied $\mathrm{TiS}_{3}$ sample was fabricated by a direct reaction of metallic titanium with elemental sulfur: $\mathrm{Ti}+3 \mathrm{~S}=\mathrm{TiS}_{3}$ in evacuated ampoules at 500-600 ${ }^{\circ} \mathrm{C}$ [41,42].

The obtained nanomaterial sample was characterized via scanning electron (SEM) microscopy (Vega3 Tescan, Brno, Czech Republic), atomic force (AFM) microscopy (AIST-NT, Zelenograd, Russia) and Raman-scattering spectroscopy (Thermo DXR, Thermo Scientific, Waltham, MA, USA).

The analysis of the distribution of metals in the tissues of experimental plants was carried out the on scanning electron microscope Neon 40 (Carl Zeiss, Jena, Germany) by energy dispersive (EDS) spectrum analysis. Sample preparation: a weighed portion of plant tissue weighing $250 \mathrm{mg}$ was ground in a cooled mortar in $0.5 \mathrm{~mL}$ of distilled water. The resulting homogenate was applied to a substrate, dried at room temperature and placed in the SEM to study.

The concentration of hydrogen sulfide in the solution was measured by the method of reverse iodometric titration. One gram of titanium trisulfide nanoribbons was added to $100 \mathrm{~mL}$ of bidistilled water, and the concentration of hydrogen sulfide in water was measured daily for 7 days.

To prepare the colloidal solution, $0.3 \mathrm{~g}$ nanoparticles portion was weighed using an analytical balance ViBRA HT (Shinko Denshi, Tokyo, Japan, (accuracy $\pm 0.0001 \mathrm{~g}$ )), poured into $100 \mathrm{~mL}$ distilled water $(\mathrm{pH}=7.1 \pm 0.2)$, stirred with a glass rod for $20 \mathrm{~s}$ and treated in an ultrasound bath, the Ultrasonic Cleaner CD-4800 (Codyson, Guangdong, China), for $2 \mathrm{~min}(70 \mathrm{~W}, 44 \mathrm{~Hz}$, volume-1.4 L). The solution was added to the growth medium to obtain $0.75,1.5,3,6$ and $15 \mu \mathrm{g} / \mathrm{L}$ nanomaterial concentrations.

For the in vitro culture initiation, plant cuttings with apical and axillary buds were used. The cuttings were washed with a surface-active agent (Tween-20) and thoroughly rinsed in distilled water. Then, the samples were cut into segments and sterilized for $40 \mathrm{~min}$ in the solution of $200 \mu \mathrm{L} \mathrm{5 \%}$ sodium hypochlorite $(\mathrm{NaOCl})$ in $200 \mathrm{~mL}$ distilled water with a subsequent rinse in distilled water. The major sterilization was performed for $15 \mathrm{~min}$ in the solution consisting of $15 \mathrm{~mL} \mathrm{5 \%} \mathrm{sodium} \mathrm{hypochlorite} \mathrm{and} 200 \mathrm{~mL}$ distilled water in a laminar flow cabinet. The samples were rinsed in sterile distilled water. The sterilized shoots were cut into $1.5-2 \mathrm{~cm}$ explants, each with a single axillary bud, and transferred into a Murashige and Skoog nutrient medium (MS0) [43]. All media formulations and plant growth regulators (PGR) were purchased from Duchefa Biochemie (Haarlem, The Netherlands).

The test tubes with the explants were placed in the growth chamber at $+24{ }^{\circ} \mathrm{C}$ under LD 16:8 photoperiod, 5000 lx light intensity and 70\% relative air humidity.

The following morphometric parameters were assessed during the cultivation period: microclone height, number of leaves, number of axillary shoots and roots and condition on a 5-point scale of visual assessment of microclones (where 1 point is unsatisfactory, 5 points is excellent). The proliferation of the obtained shoots was the next stage. For this purpose, well-developed microclones from the group treated with $1.5 \mu \mathrm{g} / \mathrm{L} \mathrm{TiS}_{3}$ were transplanted into the growth media containing the following components: $0.2 \mathrm{mg} / \mathrm{L}$ benzylaminopurine (BAP), $0.1 \mathrm{mg} / \mathrm{L}$ indoleacetic acid (IAA) and $0.3 \mathrm{mg} / \mathrm{L}$ gibberellic acid (GA). The synergistic effect of the phytohormones and $1.5 \mu \mathrm{g} / \mathrm{L}$ nanoparticles has also been analyzed. Histological examination was carried out by means of a VideoTesT-Morphology 4.0 hardware and software complex (Argus-BIO, St. Petersburg, Russia). 
To assess the photosynthetic system of the plants, we measured the induction of variable fluorescence of chlorophyll-a in assimilatory tissues (Fv/Fm), which makes it possible to assess the activity of the photosystem-2 chlorophyll-containing tissues and can serve as a diagnostic indicator of the state of the photosynthetic apparatus of plants. The intensity of photosynthesis of chlorophyll-containing tissues was recorded using an IFSR-2 fluorimeter (Moscow State University, Moscow, Russia) according to the Genty method [44].

Biochemical analysis was performed using a PE-5400VI spectrophotometer (Ecroschim, St. Petersburg, Russia). The activity of catalase was determined by means of the spectrophotometric technique [45], as in the assessment of the velocity of the chemical reaction of decomposition of hydrogen peroxide with catalase. A measurement of $250 \mathrm{mg}$ of raw plant material was ground in a cold porcelain mortar with $0.5 \mathrm{~mL}$ of extraction buffer solution ( $50 \mathrm{mM}$ phosphate buffer, $\mathrm{pH}=7.0$ ). The obtained homogenate was centrifuged for $5 \mathrm{~min}$ at $12,000 \times g$ and cooled down to $4{ }^{\circ} \mathrm{C}$. Amounts of $2.95 \mathrm{~mL}$ of $50 \mathrm{mM}$ phosphate buffer ( $\mathrm{pH}=7.0$ ), $30 \mu \mathrm{L}$ of extract and $20 \mu \mathrm{L}$ of $0.6 \mathrm{M}$ hydrogen peroxide were put into the spectrophotometer cuvette. Amounts of $2.95 \mathrm{~mL}$ of $50 \mathrm{mM}$ phosphate buffer $(\mathrm{pH}=7.0)$ and $30 \mu \mathrm{L}$ of extract were put into the control cuvette. Optical density was measured at the wavelength of $240 \mathrm{~nm}$ every second for $120 \mathrm{~s}$. The activity of catalase in relative units as per $1 \mathrm{~g}$ of the dry weight was determined by means of the following formula:

$$
\mathrm{A}=(\Delta \mathrm{D} \cdot \mathrm{V} \cdot \mathrm{X}) /(\mathrm{T} \cdot \mathrm{L} \cdot \mathrm{m} \cdot \Delta \mathrm{m})
$$

where $\mathrm{A}$ - enzyme activity; $\Delta \mathrm{D}$-change of optical density during the reaction $\mathrm{T}$; $\mathrm{V}$ - total volume of the obtained extract, $\mathrm{mL} ; \mathrm{X}$-correlation between the volume of the raw material put into the cuvette and the cuvette volume; T-time of reaction, s; L-optical path length of the cuvette, $\mathrm{cm} ; \mathrm{m}$-weight of vegetable material, $\mathrm{g}$, and $\Delta \mathrm{m}$ - the difference between the weight of dry vegetable material and the weight of raw vegetable material.

Rooting was the final stage of the assessment of $\mathrm{TiS}_{3}$ effects on microclones. Wellformed regenerants $\left(2-3 \mathrm{~cm}\right.$ high) were isolated and transferred to the rooting $\frac{1}{2}$ woody plant medium (WPM) in culture bottles [46]. For rhizogenesis promotion, the nanomaterial was added at $1.5 \mu \mathrm{g}$ per $1 \mathrm{~L}$ of growth medium.

All biological and biochemical parameters were measured in three biological and analytical repetitions. Each experimental and control group at each stage of the study contained 30 plants. Descriptive statistics methods included an estimate of the arithmetic mean (M) and standard deviation (S). For statistical data processing, Microsoft Excel 2010 (Descriptive Statistics software package) with one-way analysis of variance (ANOVA) at a $5 \%$ predetermined level of significance was used.

\section{Results}

\section{1. $\mathrm{TiS}_{3}$ Sample Analysis}

SEM examination of the obtained $\mathrm{TiS}_{3}$ sample (Figure $1 \mathrm{~A}$ ) showed that the material had the following mean dimensions: thickness less than $100 \mathrm{~nm}$, length 1-10 $\mu \mathrm{m}$ and width 0.4-1 $\mu \mathrm{m}$ (Figure 1B). According to the atomic force microscopy data, the nanoribbons height varied within the $10-60 \mathrm{~nm}$ range (Figure $1 \mathrm{C}$ ).

Raman spectroscopy (Figure 1D) showed prominent titanium trisulfide bands 22, thus proving that this phase was present in the sample.

\subsection{Initiation Stage}

Assessment of the effects of $\mathrm{TiS}_{3}$ nanoribbons in the growth medium at the initiation stage showed that the material is an effective sterilizing agent. We observed that $100 \%$ of the poplar $\times$ aspen hybrid and birch microshoots were uncontaminated at all the concentrations above $0.75 \mu \mathrm{g} / \mathrm{L}$, while in the control group the values were $80 \%$ and $75 \%$, respectively (Figure 2A). At 1.5 and $3 \mu \mathrm{g} / \mathrm{L} \mathrm{TiS}_{3}$, we observed a $100 \%$ survival rate of the explants (Figure 2B), though an increase in the concentration reduced the survival rate values. At $15 \mu \mathrm{g} / \mathrm{L}$, the poplar $\times$ aspen hybrid displayed the minimal survival rate value 
of $67 \%$ compared to $80 \%$ for the control, thus indicating the toxic effects of the nanomaterial against the poplar $\times$ aspen hybrid microclones.
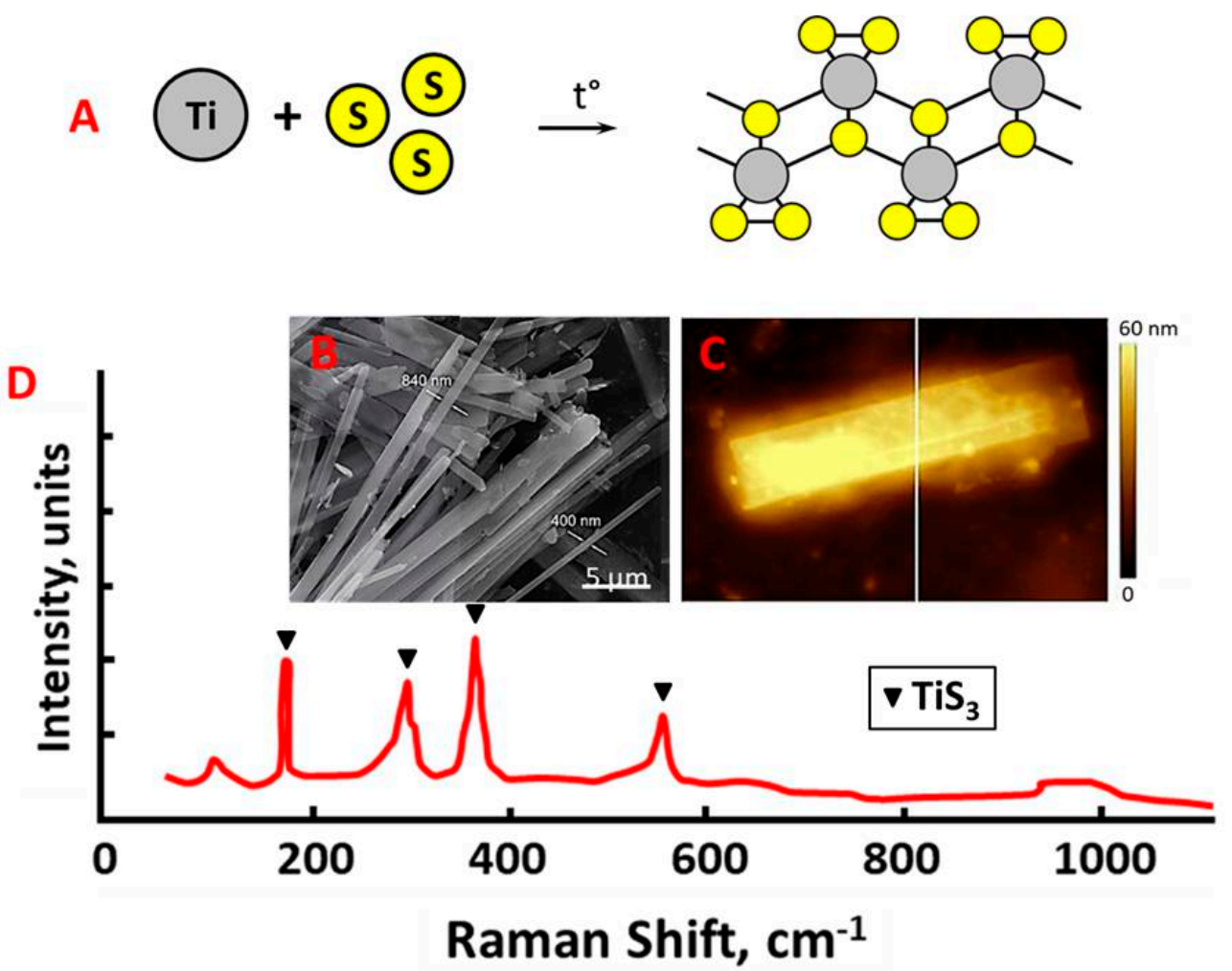

Figure 1. $\mathrm{TiS}_{3}$ nanoribbons synthesis and sample characterization: (A) reaction scheme, (B) SEM image, (C) AFM image, (D) Raman spectra.
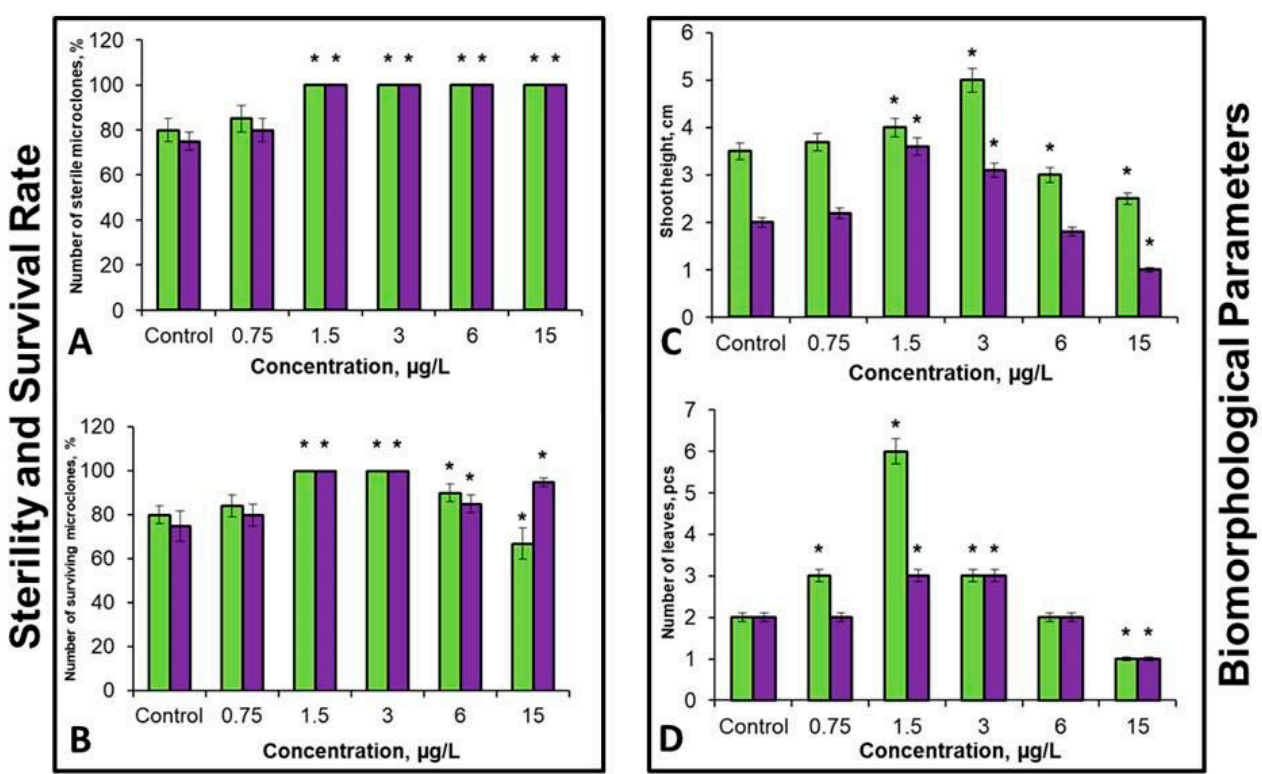

\section{Poplar $\mathrm{x}$ aspen $\quad \square$ Birch}

Figure 2. Biomorphological parameters of the microclones at the initiation stage: (A) Mean number of sterile microclones; (B) Mean number of survival microclones; (C) Mean shoot height; (D) Mean number of leaves (hereinafter the height of the column corresponds to the mean value, bar-to the standard deviation, ${ }^{*}$ is significant deviation from control). 
Analysis of the titanium trisulfide nanoribbons effects on the microclones morphometric parameters revealed that medium concentrations of the nanomaterial $(1.5 \mu \mathrm{g} / \mathrm{L}$ and $3 \mu \mathrm{g} / \mathrm{L}$ ) resulted in maximal values of the shoots length and number of leaves (Figure 2C,D). The height of poplar $\times$ aspen hybrid plants increased by $0.5-1.5 \mathrm{~cm}$, while for birch, this value was 1.6 and $1.1 \mathrm{~cm}$, respectively. However, an increase of $\mathrm{TiS}_{3}$ content in the medium up to $6 \mu \mathrm{g} / \mathrm{L}$ reduced these parameters to the control level, while at $15 \mu \mathrm{g} / \mathrm{L}$, the microshoots development was significantly suppressed.

Medium concentrations of 1.5 and $3 \mu \mathrm{g} / \mathrm{L}$ had a positive effect on other parameters of the microshoots as well. In these groups, the microclones developed axillary shoots. Poplar $x$ aspen hybrid microclones had two axillary shoots, and birch microclones produced one axillary shoot each. Furthermore, poplar $\times$ aspen hybrid microclones developed roots.

As one can see from Figure 2, the concentrations of 6 and $15 \mu \mathrm{g} / \mathrm{L}$ either had no effect on the morphological parameters or reduced them. Thus, at the initiation stage, 1.5 and $3 \mu \mathrm{g} / \mathrm{L}$ of $\mathrm{TiS}_{3}$ in the nutrient medium exposure causes a stimulating effect on the microshoots development.

\subsection{Proliferation Stage}

At the proliferation stage, cuttings were taken from the microclones from the group treated with $1.5 \mu \mathrm{g} / \mathrm{L} \mathrm{TiS}_{3}$ and were transplanted into the media containing phytohormones and the nanomaterial at the same concentration. The study results are presented in Figure 3.

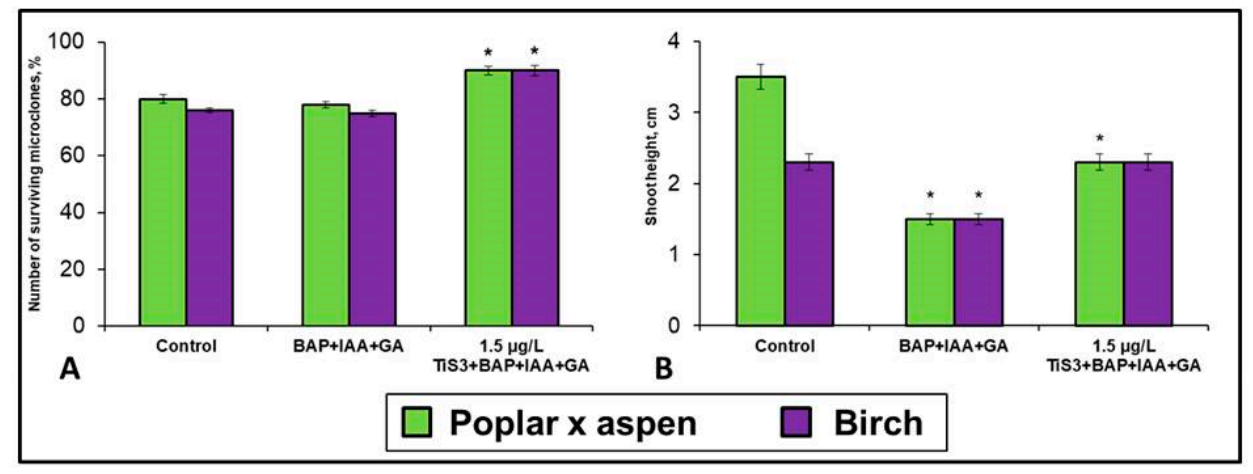

Figure 3. Biomorphological parameters of the microclones at the proliferation stage: (A) Mean number of the surviving microclones; (B) Mean shoot height.

As one can see from Figure $3 \mathrm{~A}$, the nanomaterial introduced into the growth medium increased the microclones survival rate. In the $\mathrm{TiS}_{3}$-treated groups, poplar and birch survival rate was $90 \%$, exceeding the control values by $10 \%$ and $14 \%$, respectively. In the nanomaterial-free variant, the survival rate was below the control values by $1-2 \%$. In the nanomaterial-free medium, we observed the lowest height increment (Figure 3B). More specifically, the heights were $1.5 \mathrm{~cm}$ for both hybrid poplar and birch microclones, as compared to 3.5 and $2.3 \mathrm{~cm}$ in the control groups. When we added the nanomaterial, we still observed the suppressive impact on the hybrid poplar, though it was less evident than in the previous case. The height of birch microclones in the $\mathrm{TiS}_{3}$-treated group was not significantly different from the control.

The impact of titanium trisulfide on axillary shoots and leaves formation was diverse. During the assessment of the formation of additional shoots, their absence was noted in the control variants, both poplar $\times$ aspen and birch. When phytohormones were added to the medium, three shoots appeared in both cases. When the medium with hormones was supplemented with $1.5 \mu \mathrm{g} / \mathrm{L} \mathrm{TiS}_{3}$, the indicator in poplar $\times$ aspen microclones increased to four and decreased to two in birch.

The number of leaves in poplar $\times$ aspen averaged four, regardless of the composition of the medium; however, in the case of birch, the nanomaterial had an inhibitory effect again: two leaves compared with three in the control variant. The largest number of leaves 
(four leaves) was in the group with phytohormones. Thus, the species-dependent effect of the nanomaterial is noted.

Histological examination of poplar $\times$ aspen hybrid microclones leaves (Figure 4) revealed an increase in the area and in degree of stomatal opening in the $\mathrm{TiS}_{3}$-treated group against lower stomatal area and density in the control group. Most probably, the observed increase in the stomatal opening area and degree of stomatal opening compensates for the lower number of stomata per unit area.

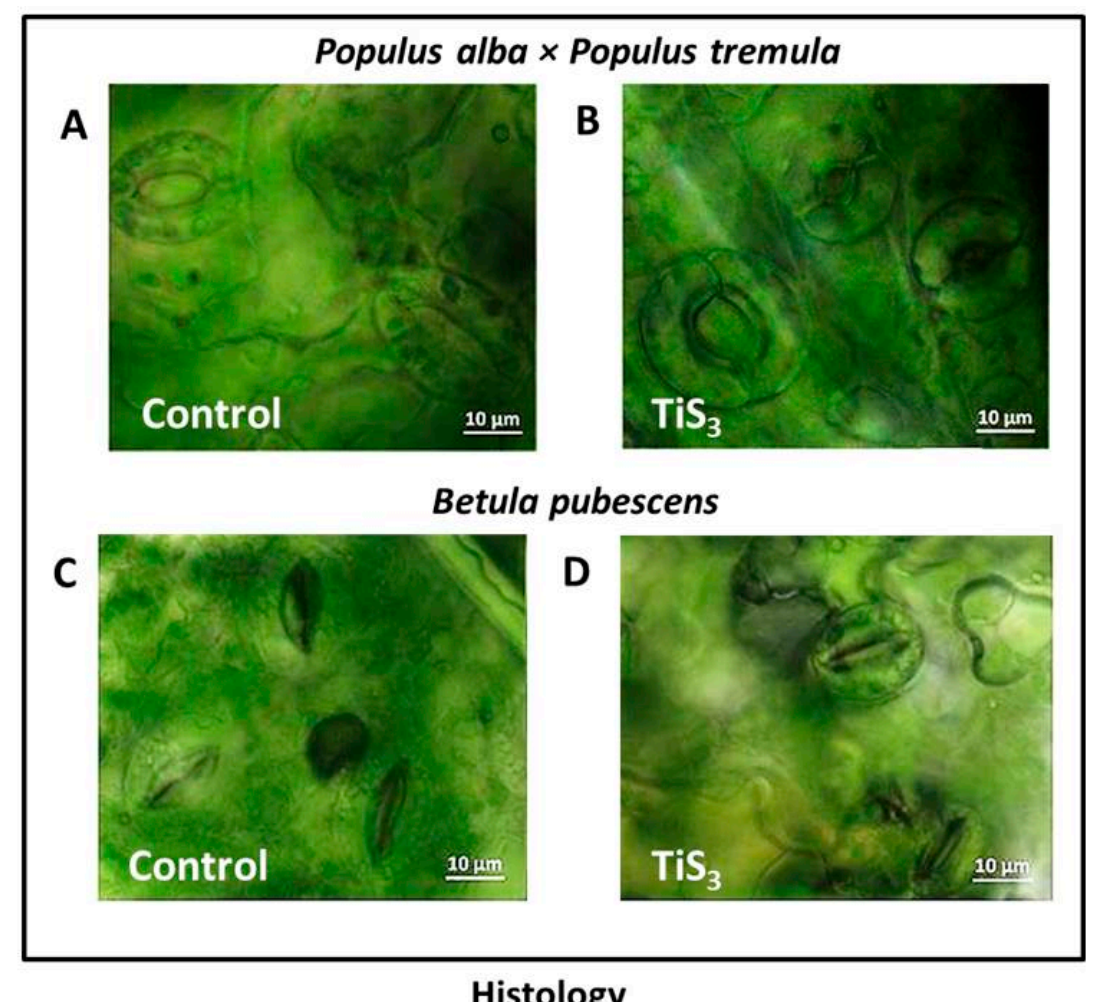

Figure 4. Stomata of the leaves of the studied plants. Hybrid poplar $\times$ aspen: (A) control, (B) $\mathrm{TiS}_{3}$; Downy birch: (C) control, (D) $\mathrm{TiS}_{3}$.

Furthermore, the nanomaterial in the growth medium decreased the leaf lamina thickness and stem diameter and, as we have already mentioned, reduced the regenerants general condition values by one point.

Upon examination of the downy birch leaf lamina histological parameters, one can assume that the $\mathrm{TiS}_{3}$-treated plants are more stress resistant than the regenerants from other groups. This is evidenced by a comparatively high degree of stomatal pore opening coupled with high stomatal density per $\mathrm{mm}^{2}$ (Table 1 ). In addition, $\mathrm{TiS}_{3}$ nanoribbons in the growth medium increased the leaf lamina thickness and stem diameter; these are the indications of a better adaptive potential of the plants from this group.

The analysis of photosystem II and enzyme activity revealed no significant effects of titanium trisulfide upon the studied parameters in poplar $\times$ aspen hybrid microclones (Figure 5). At the same time, the birch regenerants displayed a large rise in photosystem II activity- 0.55 units as compared to 0.34 units in the control group (Figure 5A) - and catalase activity -2.94 units/mg dry weight compared to 2.05 units/mg dry weight in control (Figure 5B). 
Table 1. $\mathrm{TiS}_{3}$ effects to the histomorphological parameters of the microclones at the proliferation stage.

\begin{tabular}{|c|c|c|c|c|}
\hline \multirow{2}{*}{ Parameters } & \multicolumn{2}{|c|}{ Hybrid Poplar $\times$ Aspen } & \multicolumn{2}{|c|}{ Downy Birch } \\
\hline & Control & Hormones $+\mathrm{TiS}_{3}$ & Control & Hormones $+\mathrm{TiS}_{3}$ \\
\hline Stomatal pore area, $\mu \mathrm{m}^{2}$ & $74.88 \pm 5.1$ & $86.06 \pm 3.2$ & $86.04 \pm 5.32$ & $142.94 \pm 6.24$ \\
\hline Stomatal area, $\mu \mathrm{m}^{2}$ & $553.41 \pm 16.4$ & $499.88 \pm 15.1$ & $1208.93 \pm 76.31$ & $1151.28 \pm 69.45$ \\
\hline Stomatal density, pcs. $/ \mathrm{mm}^{2}$ & $5.18 \pm 0.9$ & $3.99 \pm 0.7$ & $2.99 \pm 0.5$ & $2.59 \pm 0.3$ \\
\hline $\begin{array}{c}\text { Degree of stomatal pore opening, S } \\
\text { stom./S open }\end{array}$ & $0.13 \pm 0.01$ & $0.17 \pm 0.01$ & $0.07 \pm 0.005$ & $0.12 \pm 0.008$ \\
\hline Leaf lamina thickness, $\mu \mathrm{m}$ & $100.06 \pm 9.6$ & $89.71 \pm 5.8$ & $65.07 \pm 4.46$ & $71.89 \pm 3.04$ \\
\hline Stem diameter, $\mu \mathrm{m}$ & $1206.38 \pm 75.9$ & $1193.50 \pm 63.1$ & $630.90 \pm 28.18$ & $810.13 \pm 69.23$ \\
\hline
\end{tabular}

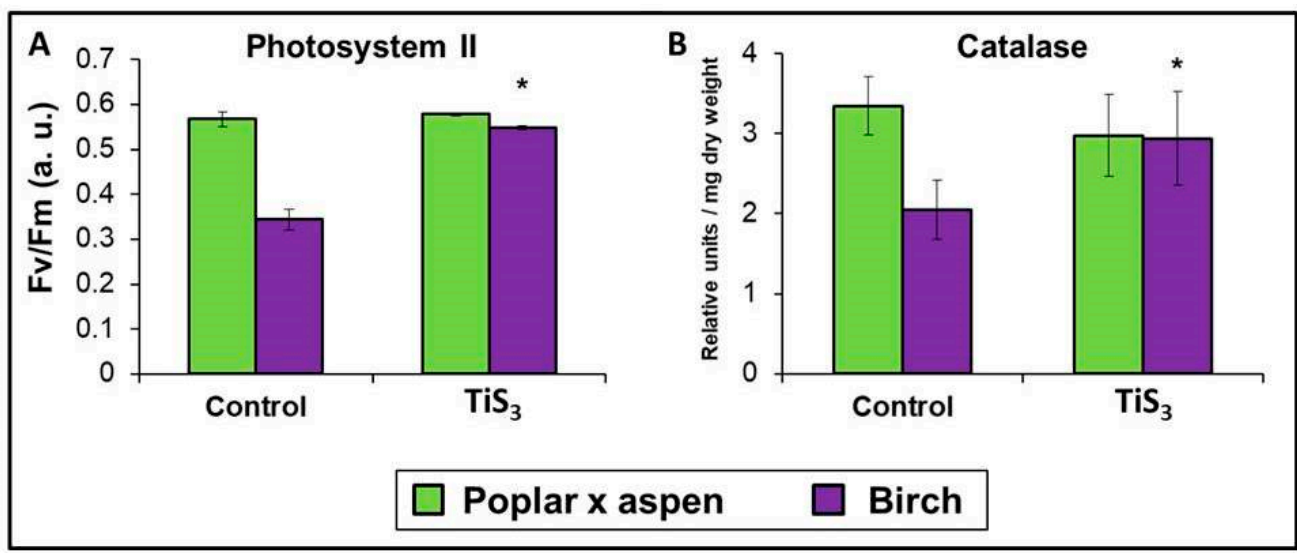

Figure 5. Microclones parameters: (A) photosystem II activity, (B) catalase activity ${ }^{*}$ is significant deviation from control).

The results of histological and biochemical examinations show that the $\mathrm{TiS}_{3}$ nanoparticles in the growth medium had no significant effect on the poplar $\times$ aspen hybrid microclones. The noted lower stomatal number and area was compensated by an increase in the stomatal density and degree of their opening. In this case, slightly lower values of leaf lamina thickness and stem diameter were observed as well. The nanomaterial had no statistically significant effect on the measured biochemical parameters. On the other hand, both histological and biochemical parameters of the birch microclones were strongly affected by $\mathrm{TiS}_{3}$ exposure. We observed a higher degree of stomatal pore opening coupled with high stomatal density per $\mathrm{mm}^{2}$, the leaf lamina thickness and stem diameter values were higher, and the material had a pronounced stimulating effect on the photosystem II and catalase activity compared to the control group. All these could be indicative of a better stress resistance of the $\mathrm{TiS}_{3}$-treated birch microclones.

\subsection{Rooting Stage}

For rooting stimulation, we added $1.5 \mu \mathrm{g} / \mathrm{L}$ of $\mathrm{TiS}_{3}$ per $1 \mathrm{~L}$ of nutrient medium. All the poplar $\times$ aspen hybrid microclones exposed to $\mathrm{TiS}_{3}$ rooted within three weeks and developed, on average, four roots, while in the control group only $50 \%$ of all the microclones rooted, developing only one root each (Table 2). In the case of birch, rhizogenesis was observed in $98 \%$ of the microclones and the plantlets developed, on average, three roots. In the control group, only $35 \%$ of plantlets developed roots (on average, one root per explant). In the $\mathrm{TiS}_{3}$-exposed group the microclones were in excellent general condition. 
Table 2. $\mathrm{TiS}_{3}$ effects at the rooting stage.

\begin{tabular}{|c|c|c|c|c|c|c|c|c|}
\hline \multirow{2}{*}{ Variant } & \multicolumn{2}{|c|}{$\begin{array}{c}\text { Number of Surviving } \\
\text { Microclones, } \%\end{array}$} & \multicolumn{2}{|c|}{$\begin{array}{c}\text { Number of Microclones } \\
\text { with Roots, } \%\end{array}$} & \multicolumn{2}{|c|}{$\begin{array}{c}\text { Number of Roots Per } \\
\text { Explant }\end{array}$} & \multicolumn{2}{|c|}{$\begin{array}{c}\text { Microclones Condition } \\
\text { According to a 5-Point Scale }\end{array}$} \\
\hline & Poplar $\times$ Aspen & Birch & Poplar $\times$ Aspen & Birch & Poplar $\times$ Aspen & Birch & Poplar $\times$ Aspen & Birch \\
\hline Control & 100 & 100 & $50 \pm 3$ & $35 \pm 5$ & 1 & 1 & 4 & 4 \\
\hline $\mathrm{TiS}_{3}$ & 100 & 100 & 100 & $98 \pm 1$ & 4 & 3 & 5 & 5 \\
\hline
\end{tabular}

\subsection{Proliferation Stage}

To determine the mechanisms of the effect of nanoribbons on the roots of shoots, we analyzed the accumulation of elements in them by EDS (Figure 6A,B). We found no difference in the accumulation of elements in the control and experimental samples. The exception was the homogenates of the plant roots of both experimental groups, where we found the accumulation of sulfur, in contrast to the control. Figure $6 \mathrm{~B}$ shows a map of the distribution of sulfur in the homogenate, from which it can be seen that sulfur is diffusely distributed. This means that it uptakes in the roots in an ionic form, separate from titanium, which was not detected in the samples.
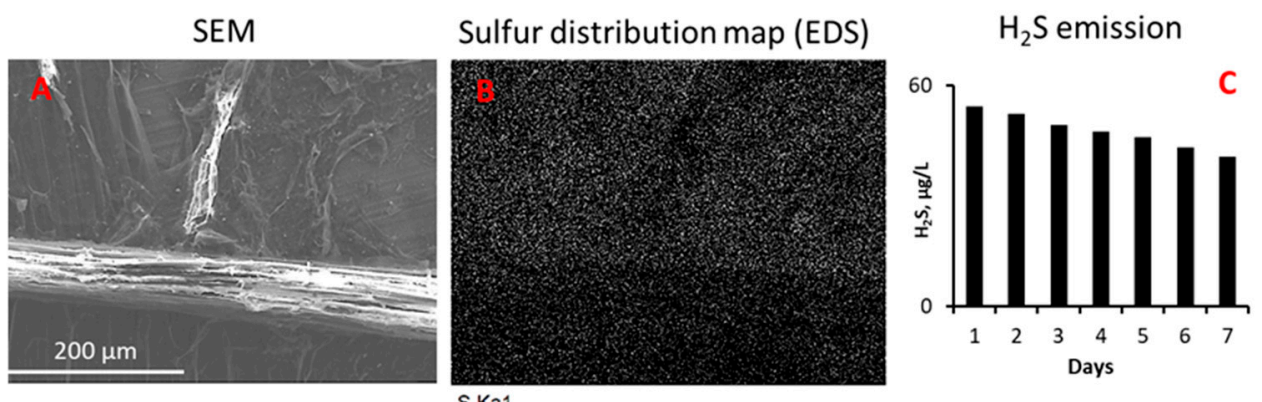

Figure 6. (A) SEM image of birch root sample homogenate (1.5 $\mu \mathrm{g} / \mathrm{L} \mathrm{TiS}_{3}$-exposed group), (B) EDS sulfur distribution map, (C) emission of hydrogen sulfide from titanium trisulfide nanoribbons in bidistilled water for 7 days.

To clarify the problem of hydrogen sulfide emission from the surface of titanium trisulfide nanoribbons into water, we carried out a model experiment, which showed that hydrogen sulfide is released into water with a slowly decreasing intensity (Figure 6C).

\section{Discussion}

Thus, our study has revealed that titanium trisulfide is a powerful sterilizing agent, because at the initiation stage, $100 \%$ of the microshoots were uncontaminated at all the concentrations above $0.75 \mu \mathrm{g} / \mathrm{L}$, and in the $1.5 \mu \mathrm{g} / \mathrm{L}$ and $3 \mu \mathrm{g} / \mathrm{L}$ variants, we observed a $100 \%$ survival rate of the explants, while higher concentrations either had no impact or produced toxic effects. The sterilizing properties of $\mathrm{TiS}_{3}$ can be connected with the antimicrobial activities of titanium dioxide [47,48], forming on the nanoribbons surfaces as a result of their oxidizing in aqueous media. It is known that the photocatalytic activity of titanium dioxide nanoparticles prevents the fungal colonization of wood treated with suspensions of nanoparticles for a long time compared to untreated wood [49].

The same medium concentrations stimulated the shoots growth and axillary shoots formation. One should also note that hybrid poplars formed roots at this stage. On the other hand, a further increase in the nanomaterial concentration produced an adverse effect: $15 \mu \mathrm{g} / \mathrm{L} \mathrm{TiS}_{3}$ significantly suppressed the microclones development. At the proliferation stage, exposure to $\mathrm{TiS}_{3}$ either had no impact on the plant development or displayed a suppressing activity. At the rooting stage the nanoribbons stimulated rhizogenesis, increasing the number of roots in poplar $\times$ aspen hybrid microclones by twofold, while in downy birch microclones, we observed almost a threefold increase in the number of roots compared to the control values. The high tolerance of birch to the effects of nanomaterials can be associated with the high adaptability of these woody plants [50]. It is known that 
birch belongs to pioneer plants, which, in particular, are the first to populate burnedout areas [51,52]. Taking into account the fact that forest fires are a natural source of nanoparticles, primarily carbon ones [53], it can be assumed that species such as birch have a pre-adaptation to the effects of nanoparticles in high concentrations in soils. Note that titanium trisulfide nanoribbons in size, shape and physicomechanical properties resemble graphene nanoribbons or carbon nanotubes. However, this hypothesis needs further research.

It was revealed that $\mathrm{TiS}_{3}$ nanoribbons do not penetrate into the root system of microclones, but they are partially destroyed in the cultivation medium with the release of low-molecular sulfur compounds, which we found in the root homogenate. Probably the effect of sulfur compounds explains the observed stimulation of rhizogenesis, as well as the sterilizing effect, which is discussed in more detail below.

Furthermore, the nanomaterial improved the overall condition of the studied microplants. The phytostimulating properties of titanium-containing nanoparticles has been reported before $[54,55]$. It has been shown that $\mathrm{TiO}_{2}$ nanoparticles can reduce oxidative damage via $\mathrm{H}_{2} \mathrm{O}_{2}$ content reduction and antioxidant enzymes activity stimulation [56]. It has also been shown that low concentrations of Ti enhance crop productivity by stimulating the activity of certain enzymes, increasing chlorophyll content and photosynthetic activity and boosting nutrient uptake and stress resistance [57]. Perhaps this explains the observed stimulation of photosystem II and an increase in catalase activity in birch.

The possible mechanism of the sterilizing effect of $2 \mathrm{D}$ transition metal trichalcogenides was proposed in our recent work [40]. We have explained the antibacterial effects of $\mathrm{ZrS}_{3}$ nanosheets by the aqueous hydrolysis, which resulted in the formation of $\mathrm{ZrOx}$ on the surface of $\mathrm{ZrS}_{3}$ particles and the release of toxic $\mathrm{H}_{2} \mathrm{~S}$. The XPS analysis confirmed the formation of $\mathrm{ZrOx}$, wherein toxicity in aqueous solutions may also increase over time due to hydrolysis and the formation of $\mathrm{H}_{2} \mathrm{~S}$. Perhaps this mechanism can explain the sterilizing effect of $\mathrm{TiS}_{3}$. This version is supported by the slow release of hydrogen sulfide from titanium trisulfide nanoribbons into water and by the presence of diffuse sulfur in the roots of plants from the experimental groups, which we described in the previous section. Hydrogen sulfide plays a signaling role in higher plants, it mediates persulfidation, a posttranslational modification and regulates wide range of physiological functions, including root growth and development [58-60], and the beneficial effects of $\mathrm{H}_{2} \mathrm{~S}$ are mainly caused by the stimulation of antioxidant systems [61]. Therefore, the protective and stimulating effects of titanium trisulfide as well as its toxicity in high concentrations can be explained by the release of hydrogen sulfide as a result of aqueous hydrolysis of nanoribbons and its effect on plants. The hydrogen sulfide and titanium dioxide nanoparticles formed during hydrolysis of nanoribbons likely have a combined effect. As a long-term source of slow emission of hydrogen sulfide into aqueous solutions, titanium trisulfide nanoribbons and other 2D transition metal trichalcogenides may be of interest for biotechnology, agriculture and biomedicine.

Thus, our study has shown through the example of poplar $\times$ aspen hybrid and downy birch microclones the effectiveness of the application of titanium trisulfide nanoribbons as a sterilizing and stimulating agent at the initiation stage and as a rhizogenesis-activating agent at the rooting stage. However, concentration-dependant toxic effects manifesting themselves through the microclones viability suppression have been discovered. We have identified specificity in the studied plants' reactions to $\mathrm{TiS}_{3}$ exposure, i.e., downy birch is more tolerant than the poplar $\times$ aspen hybrid. The assessment of the biological effects produced by $\mathrm{TiS}_{3}$ nanoribbons at further stages of ontogenetic development, as well as the identification of the mechanisms of their action, requires additional studies.

Author Contributions: Conceptualization, A.A.G.; Methodology, O.V.Z., A.A.G., D.S.M. and A.V.S.; Software, A.A.G.; Validation, O.V.Z., A.A.G., and D.S.M.; Formal Analysis, O.V.Z. and N.S.S.; Investigation, O.V.Z., A.A.G., D.S.M., A.V.S. and N.S.S.; Resources, A.A.G., D.S.M. and A.V.S.; Data curation, O.V.Z., A.A.G. and N.S.S.; Writing-Original Draft Preparation, O.V.Z. and A.A.G.; Writing-Review and Editing, O.V.Z., A.A.G., D.S.M. and S.M.M.; Visualization: O.V.Z., A.A.G., D.S.M. and A.V.S.; 
Supervision, O.V.Z. and A.A.G.; Project administration, A.A.G. All authors have read and agreed to the published version of the manuscript.

Funding: This research was funded by the Russian Science Foundation, grant number 21-14-00233, https: / rscf.ru/project/21-14-00233/ (accessed on 24 May 2021), as part of the SEM and EDS studies of the plant samples.

Conflicts of Interest: The authors declare no conflict of interest.

\section{References}

1. Beck, P.; Caudullo, G.; de Rigo, D.; Tinner, W. Betula pendula, Betula Pubescens and Other Birches in Europe: Distribution, Habitat, Usage and Threats; Publication Office of the European Union: Luxembourg, 2016.

2. Skovsgaard, J.P.; Johansson, U.; Holmström, E.; Tune, R.M.; Ols, C.; Attocchi, G. Effects of Thinning Practice, High Pruning and Slash Management on Crop Tree and Stand Growth in Young Even-Aged Stands of Planted Silver Birch (Betula pendula Roth). Forests 2021, 12, 225. [CrossRef]

3. Kutsokon, N.; Libantová, J.; Rudas, V.; Rashydov, N.; Grodzinsky, D.; Ďurechová, D. Advancing protocols for poplars in vitro propagation, regeneration and selection of transformants. J. Microbiol. Biotechnol. Food Sci. 2013, 2, 1447-1454.

4. Rosso, L.; Facciotto, G.; Bergante, S.; Vietto, L.; Nervo, G. Selection and testing of Populus alba and Salix spp. as bioenergy feedstock: Preliminary results. Appl. Energy 2013, 102, 87-92. [CrossRef]

5. Castiglione, S.; Todeschini, V.; Franchin, C.; Torrigiani, P.; Gastaldi, D.; Cicatelli, A.; Rinaudo, C.; Berta, G.; Biondi, S.; Lingua, G. Clonal differences in survival capacity, copper and zinc accumulation, and correlation with leaf polyamine levels in poplar: A large-scale field trial on heavily polluted soil. Environ. Pollut. 2009, 157, 2108-2117. [CrossRef] [PubMed]

6. Rédei, K. Early performance of promising white poplar (Populus alba) clones in sandy ridges between the rivers Danube and Tisza in Hungary. For. Int. J. For. Res. 2000, 73, 407-413. [CrossRef]

7. Park, Y.; Bonga, J. Application of Somatic Embryogenesis in Forest Management and Research. In Proceedings of the IUFRO Working Party 2.09.02: "Somatic Embryogenesis of Trees" Conference, Suwon, Korea, 19-21 August 2010; pp. 3-8.

8. Zeng, F.; Qian, J.; Luo, W.; Zhan, Y.; Xin, Y.; Yang, C. Stability of transgenes in long-term micropropagation of plants of transgenic birch (Betula platyphylla). Biotechnol. Lett. 2009, 32, 151-156. [CrossRef]

9. Ziauka, J.; Kuusiene, S. Multiplication and growth of hybrid poplar (Populus alba $\times$ P. tremula) shoots on a hormone-free medium. Acta Biol. Hung. 2014, 65, 346-354. [CrossRef]

10. Thompson, D. Challenges for the large-scale propagation of forest trees by somatic embryogenesis-A review. In Proceedings of the 3rd International Conference of the IUFRO Unit 2.09.02 on "Woody Plant Production Integrating Genetic and Vegetative Propagation Technologies", Vitoria-Gasteiz, Spain, 8-12 September 2014; pp. 81-91.

11. Ballester, A.; Corredoira, E.; Vieitez, A.M. Limitations of Somatic Embryogenesis in Hardwood Trees; National Institute of Forest Science: Seoul, Korea, 2016.

12. Vaičiukynè, M.; Žiauka, J.; Žūkienè, R.; Vertelkaitè, L.; Kuusienè, S. Abscisic acid promotes root system development in birch tissue culture: A comparison to aspen culture and conventional rooting-related growth regulators. Physiol. Plant. 2019, 165, 114-122. [CrossRef]

13. Paulraj, S.; Yeung, E.C. Improved shoot regeneration from root explants using an abscisic Acid-containing medium. Methods Mol. Biol. 2012, 877, 183-189. [CrossRef]

14. Wang, H.; Wang, C.; Liu, H.; Tang, R.; Zhang, H. An efficient Agrobacterium-mediated transformation and regeneration system for leaf explants of two elite aspen hybrid clones Populus alba $\times$ P. berolinensis and Populus davidiana $\times$ P. bolleana. Plant Cell Rep. 2011, 30, 2037-2044. [CrossRef]

15. Vinocur, B.; Carmi, T.; Altman, A.; Ziv, M. Enhanced bud regeneration in aspen (Populus tremula L.) roots cultured in liquid media. Plant Cell Rep. 2000, 19, 1146-1154. [CrossRef]

16. De Block, M. Factors Influencing the Tissue Culture and the Agrobacterium tumefaciens-Mediated Transformation of Hybrid Aspen and Poplar Clones. Plant Physiol. 1990, 93, 1110-1116. [CrossRef] [PubMed]

17. Álvarez, S.P.; Tapia, M.A.M.; Vega, M.E.G.; Ardisana, E.F.H.; Medina, J.A.C.; Zamora, G.L.F.; Bustamante, D.V. Nanotechnology and Plant Tissue Culture. In Plant Nanobionics: Volume 1, Advances in the Understanding of Nanomaterials Research and Applications; Prasad, R., Ed.; Springer International Publishing: Berlin/Heidelberg, Germany, 2019; pp. 333-370.

18. Wang, P.; Lombi, E.; Zhao, F.-J.; Kopittke, P.M. Nanotechnology: A New Opportunity in Plant Sciences. Trends Plant Sci. 2016, 21, 699-712. [CrossRef] [PubMed]

19. Aslani, F.; Bagheri, S.; Muhd Julkapli, N.; Juraimi, A.; Hashemi, F.; Baghdadi, A. Effects of Engineered Nanomaterials on Plants Growth: An Overview. Sci. World J. 2014, 2014, 641759. [CrossRef]

20. Morales-Díaz, A.; Ortega-Ortíz, H.; Juárez Maldonado, A.; cadenas-pliego, G.; González-Morales, S.; Benavides-Mendoza, A. Application of nanoelements in plant nutrition and its impact in ecosystems. Adv. Nat. Sci. Nanosci. Nanotechnol. 2017, 8, 1-13. [CrossRef]

21. Nemček-Korenkova, L.; Šebesta, M.; Urík, M.; Kolencik, M.; Kratošová, G.; Bujdoš, M.; Vávra, I.; Dobrocka, E. Physiological response of culture media-grown barley (Hordeum vulgare L.) to titanium oxide nanoparticles. Acta Agric. Scand. Sect. B Soil Plant. Sci. 2017, 67, 1-7. [CrossRef] 
22. Kim, D.H.; Gopal, J.; Sivanesan, I. Nanomaterials in plant tissue culture: The disclosed and undisclosed. RSC Adv. 2017, 7, 36492-36505. [CrossRef]

23. Mahna, N.; Zununi Vahed, S.; Khani, S. Plant In vitro Culture goes Nano: Nanosilver-Mediated Decontamination of Ex vitro Explants. Nanomed. Nanotechnol. 2013, 4, 1000161. [CrossRef]

24. Rostami, A.A.; Shahsavar, A. Nano-Silver Particles Eliminate the in vitro Contaminations of Olive 'Mission' Explants. Asian J. Plant Sci. 2009, 8, 505-509. [CrossRef]

25. Safavi, K.; Mortazaeinezahad, F.; Esfahani, M.; Asgari, M. In Vitro Antibacterial Activity of Nanomaterial for Using in Tobacco Plants Tissue Culture. World Acad. Sci. Eng. Technol. 2011, 55, 372-373. [CrossRef]

26. Sarmast, M.K.; Niazi, A.; Salehi, H.; Abolimoghadam, A. Silver nanoparticles affect ACS expression in Tecomella undulata in vitro culture. Plant Cell Tissue Organ. Cult. (PCTOC) 2015, 121, 227-236. [CrossRef]

27. Talankova-Sereda, T.; Liapina, K.; Shkopinskij, E.; Ustinov, A.; Kovalyova, A.; Dulnev, P.; Kucenko, N. The Influence of Cu иCо Nanoparticles on Growth Characteristics and Biochemical Structure of Mentha Longifolia In Vitro. In Nanophysics, Nanophotonics, Surface Studies, and Applications; Fesenko, O., Yatsenko, L., Eds.; Springer Proceedings in Physics; Springer: Cham, Switzerland, 2016; Volume 183. [CrossRef]

28. Javed, R.; Usman, M.; Yücesan, B.; Zia, M.; Gürel, E. Effect of zinc oxide (ZnO) nanoparticles on physiology and steviol glycosides production in micropropagated shoots of Stevia rebaudiana Bertoni. Plant Physiol. Biochem. PPB 2017, 110, 94-99. [CrossRef] [PubMed]

29. Ghorbanpour, M.; Hadian, J. Multi-walled carbon nanotubes stimulate callus induction, secondary metabolites biosynthesis and antioxidant capacity in medicinal plant Satureja khuzestanica grown in vitro. Carbon 2015, 94, 749-759. [CrossRef]

30. Khodakovskaya, M.V.; de Silva, K.; Biris, A.S.; Dervishi, E.; Villagarcia, H. Carbon nanotubes induce growth enhancement of tobacco cells. ACS Nano 2012, 6, 2128-2135. [CrossRef] [PubMed]

31. Tripathi, D.; Gaur, S.; Singh, S.; Singh, S.; Pandey, R.; Singh, D.V.; Sharma, N.; Prasad, S.; Dubey, N.; Chauhan, D. An overview on manufactured nanoparticles in plants: Uptake, translocation, accumulation and phytotoxicity. Plant Physiol. Biochem. 2016, 110, 2-12. [CrossRef]

32. Serrano, L.; Feregrino-Perez, A.; Guevara-Gonzalez, R.; Mendoza, S.; Escalante, K. Nanoparticles in Agroindustry: Applications, Toxicity, Challenges, and Trends. Nanomaterials 2020, 10, 1654. [CrossRef]

33. Raliya, R.; Nair, R.; Chavalmane, S.; Wang, W.-N.; Biswas, P. Mechanistic evaluation of translocation and physiological impact of titanium dioxide and zinc oxide nanoparticles on the tomato (Solanum lycopersicum L.) plant. Metallomics 2015, 7, 1584-1594. [CrossRef] [PubMed]

34. Samadi, N.; Yahyaabadi, S.; Rezayatmand, Z. Effect of $\mathrm{TiO}_{2}$ and $\mathrm{TiO}_{2}$ nanoparticle on germination, root and shoot length and photosynthetic pigments of Mentha piperita. Int. J. Plant Soil Sci. 2014, 3, 408-418. [CrossRef]

35. Castiglione, M.; Giorgetti, L.; Geri, C.; Cremonini, R. The effects of nano- $\mathrm{TiO}_{2}$ on seed germination, development and mitosis of root tip cells of Vicia narbonensis L.and Zea mays L. J. Nanopart. Res. 2011, 13, 2443-2449. [CrossRef]

36. Wang, S.; Kurepa, J.; Smalle, J. Ultra-small $\mathrm{TiO}_{2}$ nanoparticles disrupt microtubular networks in Arabidopsis thaliana. Plant Cell Environ. 2011, 34, 811-820. [CrossRef]

37. Li, Y.; Jin, Q.; Yang, D.; Cui, J. Molybdenum Sulfide Induce Growth Enhancement Effect of Rice (Oryza sativa L.) through Regulating the Synthesis of Chlorophyll and the Expression of Aquaporin Gene. J. Agric. Food Chem. 2018, 66, 4013-4021. [CrossRef] [PubMed]

38. Evlakov, P.; Fedorova, O.; Grodetskaya, T.; Zakharova, O.; Gusev, A.; Krutyakov, Y.; Baranov, O. Influence of Copper Oxide and Silver Nanoparticles on Microclonal Sprouts of Downy Birch (Betula pubescens Ehrh.). Nanotechnol. Russ. 2020, 15, 476-482. [CrossRef]

39. Zakharova, O.; Kolesnikova, E.; Muratov, D.; Gusev, A. Stimulating and toxic effects of graphene oxide on Betula pubescens microclones. IOP Conf. Ser. Earth Environ. Sci. 2020, 595, 012010. [CrossRef]

40. Zakharova, O.V.; Gusev, A.A.; Abourahma, J.; Vorobeva, N.S.; Sokolov, D.V.; Muratov, D.S.; Kuznetsov, D.V.; Sinitskii, A. Nanotoxicity of $\mathrm{ZrS}_{3}$ Probed in a Bioluminescence Test on E. coli Bacteria: The Effect of Evolving $\mathrm{H}_{2} \mathrm{~S}$. Nanomaterials 2020, 10, 1401. [CrossRef]

41. Ferrer, I.; Ares, J.R.; Clamagirand, J.; Barawi, M.; Sanchez, C. Optical properties of titanium trisulphide (TiS 3 ) thin films. Thin Solid Film 2013, 535, 398-401. [CrossRef]

42. Lipatov, A.; Wilson, P.; Shekhirev, M.; Teeter, J.; Netusil, R.; Sinitskii, A. Few-layer titanium trisulfide (TiS ${ }_{3}$ ) field-effect transistors. Nanoscale 2015, 7, 12291-12296. [CrossRef] [PubMed]

43. Murashige, T.; Skoog, F. A Revised Medium for Rapid Growth and Bio Assays with Tobacco Tissue Cultures. Physiol. Plant. 2006, 15, 473-497. [CrossRef]

44. Genty, B.; Briantais, J.-M.; Baker, N.R. The relationship between the quantum yield of photosynthetic electron transport and quenching of chlorophyll fluorescence. Biochim. Biophys. Acta BBA Gen. Subj. 1989, 990, 87-92. [CrossRef]

45. Aebi, H. Catalase in vitro. Methods Enzymol. 1984, 105, 121-126. [CrossRef]

46. Lloyd, G.; McCown, B. Commercially-feasible micropropagation of mountain laurel, Kalmia latifolia, by use of shoot-tip culture. Comb. Proc. Int. Plant. Propagators Soc. 1980, 30, 421-427.

47. Azizi-lalabadi, M.; Ehsani, A.; Divband, B.; Alizadeh-Sani, M. Antimicrobial activity of Titanium dioxide and Zinc oxide nanoparticles supported in 4A zeolite and evaluation the morphological characteristic. Sci. Rep. 2019, 9, 17439. [CrossRef] 
48. Durango Giraldo, G.; Cardona, A.; Zapata, J.; Santa, J.; Buitrago-Sierra, R. Titanium dioxide modified with silver by two methods for bactericidal applications. Heliyon 2019, 5, e01608. [CrossRef] [PubMed]

49. Filpo, G.; Palermo, A.; Rachiele, F.; Nicoletta, F. Preventing fungal growth in wood by titanium dioxide nanoparticles. Int. Biodeterior. Biodegrad. 2013, 85, 217-222. [CrossRef]

50. Tedla, B.; Dang, Q.-L.; Inoue, S. White birch has limited phenotypic plasticity to take advantage of increased photoperiods at higher latitudes north of the seed origin. For. Ecol. Manag. 2019, 451, 117565. [CrossRef]

51. Blarquez, O.; Carcaillet, C. Fire, fuel composition and resilience threshold in subalpine ecosystem. PLoS ONE 2010, 5, e12480. [CrossRef]

52. Heim, R.J.; Bucharova, A.; Brodt, L.; Kamp, J.; Rieker, D.; Soromotin, A.V.; Yurtaev, A.; Hölzel, N. Post-fire vegetation succession in the Siberian subarctic tundra over 45 years. Sci. Total Environ. 2021, 760, 143425. [CrossRef] [PubMed]

53. Murr, L.; Guerrero, P.A. Carbon Nanotubes in Wood Soot. Atmos. Sci. Lett. 2006, 7, 93-95. [CrossRef]

54. Chaudhary, I.J.; Singh, V. Titanium Dioxide Nanoparticles and its Impact on Growth, Biomass and Yield of Agricultural Crops under Environmental Stress: A Review. Res. J. Nanosci. Nanotechnol. 2020, 10, 1-8. [CrossRef]

55. Khater, M. Effect of Titanium Nanoparticles $\left(\mathrm{TiO}_{2}\right)$ on Growth, Yield and Chemical Constituents of Coriander Plants. Arab J. Nuclear Sci. Appl. 2015, 48, 187-194.

56. Gohari, G.; Mohammadi, A.; Akbari, A.; Panahirad, S.; Dadpour, M.R.; Fotopoulos, V.; Kimura, S. Titanium dioxide nanoparticles $\left(\mathrm{TiO}_{2} \mathrm{NPs}\right)$ promote growth and ameliorate salinity stress effects on essential oil profile and biochemical attributes of Dracocephalum moldavica. Sci. Rep. 2020, 10, 912. [CrossRef]

57. Lyu, S.; Wei, X.; Chen, J.; Wang, C.; Wang, X.; Pan, D. Titanium as a Beneficial Element for Crop Production. Front. Plant Sci. 2017, 8, 597. [CrossRef]

58. Mei, Y.; Chen, H.; Shen, W.; Shen, W.; Huang, L. Hydrogen peroxide is involved in hydrogen sulfide-induced lateral root formation in tomato seedlings. BMC Plant Biol. 2017, 17, 162. [CrossRef] [PubMed]

59. Xuan, L.; Li, J.; Wang, X.; Wang, C. Crosstalk between Hydrogen Sulfide and Other Signal Molecules Regulates Plant Growth and Development. Int. J. Mol. Sci. 2020, 21, 4593. [CrossRef] [PubMed]

60. Hu, J.; Li, Y.; Liu, Y.; Kang, D.I.; Wei, H.; Jeong, B.R. Hydrogen Sulfide Affects the Root Development of Strawberry During Plug Transplant Production. Agriculture 2020, 10, 12. [CrossRef]

61. Corpas, F.J.; Palma, J.M. $\mathrm{H}_{2} \mathrm{~S}$ signaling in plants and applications in agriculture. J. Adv. Res. 2020, 24, 131-137. [CrossRef] [PubMed] 